\title{
Accelerated Learning without Semantic Similarity: Indirect Objects
}

\begin{abstract}
ANAT NINIO*
Abstract

The hypothesis was tested that transfer and facilitation of learning in early syntactic development does not rely on semantic analogy among the items. The study focused on the verb-indirect object (VI) construction. Longitudinal naturalistic speech corpora of $14 \mathrm{He}$ brew-speaking children (1;04-2;08) were analyzed, 9 females and 5 males, White and predominantly middle class. There was facilitation of learning among the first 10 verbs in the VI pattern, as evidenced by the accelerating growth curves. However, there was much semantic variability among the 10 indirect objects, and most had no semantically similar antecedents in the same construction. The results indicate that facilitation of learning of early syntax is most probably not mediated by semantic similarity.
\end{abstract}

Keywords: syntactic development, semantics, transfer of learning, analogy, constructions

\section{Introduction}

Children's ability to engage in analogy-making in developing a grammar has been a focus of growing interest (e.g., Fisher 1996; Gentner \& Markman 1997; Hilaire \& Kern 2002; Hirsh-Pasek \& Golinkoff 1996). One of the major contexts in which analogymaking operates is in transfer of learning.

Theoreticians of learning claim that all new learning involves transfer based on previous learning (Bransford et al. 1999). Transfer is the ability to extend what has been learned in one context to 
new contexts, by analogy (Byrnes 1996). Its effect is measured by facilitation of learning if positive, and interference with learning if negative, evidenced by changes in the speed and accuracy of learning. Facilitation is an active process and can be observed in the gradually increasing speed and decreasing error-rate of learning next exemplars (Singley \& Anderson 1989).

Recently much evidence has accumulated documenting the operation of transfer and facilitation in young children's acquisition of syntactic knowledge, revealing considerable inter-item transfer already in the earliest stages of development.

For example, McClure and Pine (2002) demonstrated that the general level of syntactic knowledge a child has at the time a new verb is learned, influences what the child learns of the new verb's combinatorial possibilities. They showed that verbs learned after children reach the MLU of 2.0, initially generate more complex utterances in terms of MLU and the number of verb-arguments expressed than the starting utterances of verbs learned earlier.

The sources of transfer are apparently other items previously learned in the same syntactic construction and even items appearing in related constructions, as long as they share some of their more important formal and semantic features with the currently learned one. There are many indications of a basically itemspecific learning in syntactic development, in particular children need to learn on a verb-by-verb basis, what kind of semantic arguments are to be expressed by what kind of phrases (e.g., Bowerman 1982; Clark 1978; Maratsos \& Chalkley 1980; Ninio 1988; Slobin 1985, Tomasello 2000); in an accusative language, the choice is between subjects, direct objects, indirect objects and oblique objects of various types. Transfer apparently facilitates the learning of this type of information from the input, on the basis of previously learned mappings and syntactic constructions, and enables the extension of previously learned patterns to novel items on the basis of similarity and analogy.

In the experimental paradigm transfer has been measured by the effect of training on the probability of children using a novel item in a particular syntactic construction without previous modeling. Childers and Tomasello (2001) showed that presenting young children with many transitive sentences in a very short time brings about considerable productive use of novel or nonce verbs in transitive constructions, without the children having first heard these test verbs in a transitive sentence. Apparently, children at the earliest stages of producing combinatory speech are quite capable of 
transferring knowledge gained through the enhanced modeling of a syntactic construction for some items, to novel items.

In the naturalistic observational paradigm, transfer has been observed in the speeding up of the learning of new word combinations after an initial period of slow advance (Bowerman 1976; Braine 1963), and especially by the acceleration of the growth curves for cumulative type frequency of particular syntactic constructions, over different participating verb types. A series of studies (Abbot-Smith \& Behrens 2003; Kiekhoefer 2002; Ninio 1999; Ninio \& Keren-Portnoy 2002) showed that the more verbs children are already able to combine in a certain syntactic pattern (such as the subject-verb-object or the passive constructions) the faster they learn new ones in the same pattern. For instance, Ninio (1999) documented the effect of transfer on the learning of the first 20 verbs in the transitive verb-object (VO) and subject-verb-object (SVO) patterns. The same acceleration recurred in the case of the two different combinatorial rules explored, demonstrating that the speed-up is specifically tied to the number of previously produced verbs in the same kind of combination. In principle, accelerated acquisition could be due to some general developmental advance to which many aspects of language acquisition are sensitive. However, a nonspecific developmental advance would not generate two temporally separate gradually-increasing graphs, each beginning with a very slow learning rate. If there were no specific effects of the particular combinatory pattern on the speed of learning, the second (SVO) graph would start with the slope already achieved by the first (VO) learning task, and learning would not slow down afresh.

The Kiekhoefer (2002) and Abbot-Smith \& Behrens (2003) studies and their findings are especially convincing as the studies used the corpora of two children, one learning English and the other German, whose observations were unusually dense: The children's speech was recorded five days a week, for one hour each time during the relevant period. As Tomasello and Stahl (2004) point out, high-density sampling provides an unusually robust and reliable basis for estimating the important developmental phenomena of age and order of acquisition.

Transfer has also been found in a connectionist simulation of the acquisition of grammatical constructions. Morris and colleagues (2000) simulated the learning of grammatical relations with a connectionist simple recurrent network, which was trained to assign semantic categories (agent or experiencer) to words in a 
series of different constructions involving action-verbs (e.g., kiss) and experience-verbs (e.g., see). They found that the system becomes productive with a grammatical construction more quickly the larger the amount of experience which it had with that particular construction, as well as the amount of experience with previously learned, simpler related constructions.

These findings join the results of several decades of research in language acquisition showing that there is transfer and facilitation besides item-specific piecemeal learning right at the start of acquisition. Accelerating acquisition has been demonstrated in most of the major domains of language development. For instance, plottings of the mean length of utterance as a function of age in longitudinally-collected samples usually slope gradually upwards (e.g., Bloom et al. 1975), showing that children get progressively better at learning new morphemes in general, and at combining them in utterances. Similarly, graphs of overall vocabulary size measured by cumulative type frequency as a function of age typically show acceleration in the initial stages of vocabulary learning (e.g., Elman et al. 1996; Nelson 1973; and see Ingram 1989, for a review). At later stages of development, the learning of new items typically slows down and the growth curves decelerate, resulting in an overall S-shaped or logistic curve (e.g., Ruhland et al. 1995).

The connectedness and systemic nature of the accumulating vocabulary has been accepted without dispute by the whole field, despite the fact that it is undoubtedly true that each vocabulary item has to be learned individually. It is only regarding the grammatical part of children's language that for some time it was assumed by some researchers that individual verbs and their combinatory patterns are not only learned in a piecemeal fashion, but also form isolated "verb islands", unrelated to each other, and that children's emerging syntactic knowledge does not organize into a system (e.g., Tomasello 2000). The recent findings demonstrate that syntactic knowledge, just like the vocabulary, is learned on the active background of previous learning, and that once learned, each piece of new information joins an interconnected network of related items of knowledge, facilitating further learning. Apparently, children's lexically specific, item-based learning of individual wordcombinations for some verbs facilitate the lexically specific, itembased learning of a similar construction for other verbs.

There are already some results showing that transfer and facilitation in syntactic acquisition might happen irrespective of the degree of semantic similarity in the stimuli to which syntactic pat- 
terns are to be learned as "response". This conclusion is based on both experimental findings and naturalistic observational data.

In two studies (Childers \& Tomasello 2001; Abbot-Smith et al. 2004) the researches presented young children with a large amount of transitive sentences in a short period of time, then tested their ability to use novel nonce-verbs in the transitive construction when the verbs were introduced to the children either in intransitive or in passive sentences. It is well known that in circumstances when no such mass training is provided, only a small minority of young children under 3 years of age use novel verbs in unmodelled syntactic constructions (e.g., Akhtar \& Tomasello 1997); this result returned in their control condition. By contrast, the $21 / 2$ year olds who underwent training in their studies produced a significant number of transitive sentences with the novel verbs. The two studies differed in the semantic similarity of the training verbs and the testing verbs. In the Childers and Tomasello study, the majority of training verbs and all testing verbs expressed caused motion. The authors interpreted the results as demonstrating that the enhanced input helped the establishment of a semantically coherent transitive schema in these young children, underlying the transfer of the transitive construction to the novel verbs. In the study by Abbot-Smith and colleagues, the testing verbs were from a different semantic class than the training verbs. While the training verbs were verbs of caused-motion (such as dropping or rolling) as were most verbs in the previous study, the testing verbs were nonce-verbs signifying light-emission and sound-emission. Despite the semantic difference between training and testing verbs, this study found the same amount of facilitation in $21 / 2$ year olds' production of transitive constructions without prior modeling as the Childres and Tomasello one. The positive results of training without semantic similarity and the lack of an effect for the degree of similarity make it questionable that semantic analogy plays a decisive role in the facilitation achieved by the enhanced input. At the very least, it is unlikely that facilitation and transfer rely on a transfer process that requires the semantics of the training and testing verbs to be closely related.

A second negative finding for the effect of semantic similarity was obtained in a recent study on the development of the transitive verb-object (VO) construction (Ninio 2005). In this study, the first 6 types of $\mathrm{VO}$ constructions in 20 Hebrew-speaking children were analyzed for the occurrence of transfer of learning and facilitation, as well as for the lexical-semantic similarity of the verbs and of the 
semantic roles of the direct objects (DO). There was facilitation of learning among the first 6 verbs in the VO pattern, as evidenced by accelerating growth curves. However, the 6 verbs belonged to a mean of 5.70 different semantic fields, hence most verbs had no semantically similar antecedents in the same construction. In addition, the semantic similarity of the DOs were also estimated, using an 8-category system including such case-categories as Patient, Theme and Effected Object. There were a mean of 3.95 different semantic roles represented among the first 6 types, meaning that 3 out of the 5 "later" DOs were learned without a single semantic antecedent.

The results of these studies suggest that facilitation of learning of early syntax is not mediated by semantic similarity, either narrowly or widely defined. This is a surprising finding, as it is widely held that semantic similarity is the dimension along which children generalize item-specific syntactic knowledge, or generate abstract syntactic schemas and constructions (e.g., Bloom et al. 1975; Bowerman 1973, 1982; Braine 1976; Brown 1973; Dabrowska 2000; Goldberg 1995, 1999; MacWhinney 1982; Morris et al. 2000; Pinker 1984, 1989; Schlesinger 1971; Tomasello 1998, 2000).

One possibility worth exploring is that the irrelevance of semantic similarity for transfer and facilitation of learning is specific to direct objects of transitive verbs. It is well known that the category of DOs is unusually varied semantically, both in Hebrew and in English (Lyons 1968: 439). In her paper on the emergence of the prototypical semantics of argument structure constructions, Goldberg (1999: 207) pointed out that, not as in the case of other kinds of constructions, simple syntactic SVO status is not very strongly associated with a typical transitive semantics such as " $\mathrm{X}$ acts on Y", but that even very frequent transitive verbs can have other types of semantics such as stative ones. In fact, in Hebrew it is difficult to find semantic criteria as to which verbs take DOs and which, indirect or oblique ones (Glinert 1989: 159). The arbitrariness means that children need to learn for each verb separately that it takes a DO, on an item-specific basis. In such circumstances, it might even be risky to rely on semantic analogy for predicting that some new verb with a meaning similar to a previously learned one will also take a DO, as the prediction will often turn out to be incorrect. Therefore, it might turn out not to be a coincidence that the negative findings regarding the effect of semantic similarity on transfer of learning reviewed above all involve transitive verbs and the constructions they participate in with their direct objects such 
as VO and SVO. It could be the case that transfer of learning of monotransitive syntax relies mostly or exclusively on similarity in the formal pattern, while other constructions, where the semantics is less randomly associated with the syntax, rely also or even mostly on semantic analogy between new and old learning tasks.

The aim of the present study was to test the role of semantic similarity in the acquisition of another basic grammatical relation, that of the indirect object (IO), or more precisely, the acquisition of the two-word construction consisting of a verb and its IO. The focus of the study was the Hebrew IO marked by the preposition le-, ('to', a bound morpheme in Hebrew), serving to express the recipient argument of ditransitive verbs, a close analogue of the English IO with to. Not as DOs, these IOs are said to have a strong semantic prototype, the recipient, both in Hebrew (Berman 1982; Glinert 1989) and in other accusative languages (e.g., Allerton 1978; Goldberg 1995; Shibatani 1996). Semantics is also important in the ad hoc or "coerced" uses of the IO construction, often expressing a beneficiary meaning (Berman 1982). The question was whether the phenomenon found for the acquisition of the transitive DO regarding facilitation without semantic similarity, will repeat in another grammatical pattern, and especially in one with pronounced semantic correlates.

\subsection{The Indirect Object in le- in Hebrew}

Hebrew is an accusative language with an SVO canonical word order. It uses several different prepositions with core-arguments of verbs. The DO is distinguished from Indirect Objects (IO) by the preposition it takes: DOs take the preposition et- when the object is definite and a zero alternative when the object is indefinite. Other core objects collectively known as IOs take one of a list of obligatory prepositions $l e-, e l-, m i-, a l-, b e-, i m, k e-$, axarey, taxat and more. IOs must appear with the proper preposition under all conditions, including definiteness, irrespective of immediate postverbal position and so forth. The relative ordering of direct and indirect objects depends on considerations of heaviness as well as definiteness and focus of the two objects, so that pronouns typically come directly after the verb (Berman 1982). Namely, not as in English, IOs cannot be expressed as a DO under any circumstances. Some of the prepositions are clitics, some particles, and some others exist in both a clitic and a particle form. Most, including le-, can be inflected for person, in which case they assume a non-cliticized prosodic form and behave like case-marked pronouns. 
The type of preposition a verbal object gets is lexically specified; in some cases the verb can freely alternate between two prepositions but mostly there is only a single preposition for each verb. Similar to the situation in English, the source of the IOprepositions are adverbial prepositions with which they are homonymous: le- and $e l$ - ('to') mark goal or direction, $m i$ - ('from') marks source, al- ('on'), be- ('in'), axarey ('behind'), taxat ('under') are locatives, im ('with') is comitative and so forth. Although the case-prepositions are heavily grammaticalized and have very little intrinsic meaning, there is a leftover semantic correlation with some of them. This applies also to the preposition $l e$ - which is the focus of the present study, which is often (but not exclusively) used for extended meanings of a goal, such as the recipient (Berman 1978; Glinert 1989).

Despite the superficial similarity of the dative IOs to locative and directional prepositional phrases which serve as adverbial modifiers, it was decided not to mix the two kinds of syntactic constructions in this study but focus on the complement-type dative IO only. It has been pointed out that the Hebrew dative complements are markedly different in important features from adverbial prepositional phrases, and they even possess certain properties of noun phrases (Borer \& Grodzinsky 1986; Botwinik-Rotem 2000). The clearest criteria for distinguishing dative $l e$-phrases from locative le-phrases involves the possibility of using the inflected pronominal form in the former but not the latter, and the possibility of substitution of the preposition le- with the preposition $e l$ which is possible only in locative le-phrases (Landau 1994). Similar criteria were used by Ben-Shachar and Grodzinsky (2003) in their work on dative complements in Hebrew.

It is worth examining the effect of the exclusion of locative adverbial phrases on the hypothesis tested in the present study. It is possible that adverbial le-phrases would have had some facilitating effect on the acquisition of indirect-object le-phrases, as AbbotSmith \& Behrens (2003) showed that other previously acquired constructions may influence ease of transfer to a new construction, as long as they share some of their formal attributes with the new pattern. Including adverbial phrases would have increased the semantic variability of the early $l e$-phrases we examined while retaining some of the facilitation from one item to another, thus reducing the potential role of semantic similarity in the facilitation process. This means that the exclusion of adverbial phrases works FOR the hypothesis that semantic similarity plays a role in transfer 
of knowledge among the different indirect objects, in case such an effect indeed operates. Thus, it was decided not to include adverbial phrases (and to leave the investigation of secondary facilitation to some other time) in order to retain the purity of the syntactic definition of the argument construction we are exploring, without hurting the chances of the semantic hypothesis to be accepted.

Besides verbs, stative predicates such as adjectives also get IOs with some of the same set of prepositions. In particular, adjectives such as cold, hungry or tired are, in Hebrew, one-place experiential or "circumstancial" predicates that take dative-marked complements as their single argument, and have no nominative-case subjects (Berman 1982; Bolinger 1973). Such experiential contents are normally expressed in an adjective-IO combination such as oar li, literally 'cold to-me (I'm cold)'. The status of the relevant dative complements is very similar to those of verbs and are considered the same phenomenon in the linguistics literature (e.g., Glinert 1989). In consequence, the IOs of adjectives was treated in this study as belonging to the same grammatical category as the IOs of verbs.

Not all IO-in-le are valency-dictated canonical dative complements. Hebrew is extremely liberal regarding the licensing of the so-called "ethical datives": in colloquial speech practically any verb can receive an indirect object expressing the beneficiary, nonparticipating affectee or malfactee, or else the autonomous agent of the action encoded by the verb (Berman 1982, 1985; Borer \& Grodzinsky 1986). For example, in the sentence Ha-vered parax li bediyuk be-yom-huledet (literally, 'the-rose bloomed to-me exactly in-birthday $=$ The rose bloomed for me exactly on my birthday'), the speaker is not an active participant in the event but rather, an outsider who is positively affected by the event. The dative complement is in no way required by the verb, syntactically or semantically; however, formally this complement is indistinguishable from the canonical or valency-required dative IOs. The semantics of the construction is not given a priori by the lexical value of the verb; Instead, it is "coerced" by the existence of the complement itself (Pustejovsky 1991). The difference between required and ad hoc dative complements is substitutability: while the canonical required dative complement must use the lexically specified preposition $l e-$, at the most exchangeable by another lexically specified preposition such as $e l$ - in some cases, the ad hoc version freely allows substitution by any other preposition with the right semantics 
such as avur, bishvil, lema'an, all three translating as for (Berman 1982).

In summary, the focus of the present study were indirect objects with the preposition le-, identified by a set of morphosyntactic criteria. Included were IOs serving as dative complements, canonical or ad hoc, excluded were directional and locative prepositional phrases.

\subsection{The Semantics of Dative Objects in Hebrew}

As is true in general crosslinguistically, the role of recipient in a transfer of possession is considered to be the prototypical semantics of the dative indirect object in Hebrew. However, beyond the prototypical recipient role, there is a great deal of variability in Hebrew in the semantics of the dative complement (Berman 1982, 1985; Borer \& Grodzinsky 1986; Botwinik-Rotem 2000; Glinert 1989; Landau 2002). Both canonical and ad hoc datives can fill the roles of addressees; the benefactee of some service; a nonparticipant affectee; an entity being attached to; an entity being joined by others; something being referred to. Dative objects can also be deprivees and malefactees. In a reflexive pattern, the dative object can represent an autonomous agent performing an act for his or her own enjoyment, or an entity performing an extended activity (the construction adding the progressive aspect). In addition, some verbs receive a dative complement in a unique or idiosyncratic manner, such as xika le- ('wait for'), hirbic le- ('hit'), hicik le('bother'), hirsha le- ('allow'), naga le- ('concern'), dama le('similar to'), qara le- ('happened to'), asur le- ('forbidden for'), matim le- ('fit'), muda le- ('aware of'), and so forth (Glinert 1989: 160). Some of the semantic variability is also found in English (e.g., Gropen et al. 1989: 212), but English does not share with Hebrew the latter's widespread use of benefactive and ethical datives.

\subsection{The Present Study and its Hypothesis}

The hypothesis of the present study was that transfer of learning in natural conditions is not, in general, mediated through semantic analogy. The study concentrated on the first 10 verbs in the verbindirect object (VI) combination produced by 14 children acquiring Hebrew as their first language.

The measure of inter-item positive transfer was, as in previous studies, the degree of acceleration in the learning curve plotting the cumulative number of different verbs in the VI construction as a 
function of age at first production. Semantic similarity was estimated according to the thematic roles of the indirect objects such as recipient or beneficiary. The hypothesis of the study was tested by assessing the relation between acceleration of learning and degree of semantic similarity among the participant items.

\section{Method}

\subsection{Sample and Language Recording}

The language corpora used in this study were the first verb-indirect object combinations with the preposition le- ('to') in the multiword speech of children acquiring Hebrew as their first language. The spontaneous speech of 14 Hebrew-speaking children was analyzed. Participants in the sample were predominantly White, middle class children aged 1;04-2;08 (9 females and 5 males). The children were observed longitudinally in naturalistic home interaction with one of their parents. Of the children, one girl (F-10) was audiotaped by her parents twice a week between $1 ; 6$ and $2 ; 4$, for 20 minutes at a time. The recordings were immediately transcribed, and contextual information added. The other 13 children were audiotaped about once a week at home for 30 minutes, beginning at about 1;8 on the average, for 8-13 months; contextual information was added to the transcriptions. The observations were augmented by parental diary records on emergent patterns. The parents were asked to report on all novel word-combinations they had not previously heard the child producing, thus ensuring that the data base will cover most or all different verbs produced by the children in a particular construction, at the date these were first heard. This method remedies the potential flaws of sparse sampling that could have otherwise biased the estimates of developmental trends. In all children the observations started before word-combinations involving IOs with $l e$ - were first produced. Each child produced at least 10 different types of verb-IO combinations until observations ended.

All utterances were transcribed in standard orthography. The corpora were then divided into utterances, based on the presence of a perceptible pause separating it from other locutions of the same speaker. All utterances of two words or more were included in the data base. Immediate repetitions of a single word within the same speaking turn were not taken as adding to the length of the utterance. Utterances in which a child makes a hesitation-pause between words are considered word-combinations, but "vertical con- 
structions", in which two words belong to separate single-word turns at speech, were not so classified.

Child utterances were annotated during and also immediately after observation with detailed contextual comments regarding the communicative use of the utterance. Excluded from the present analysis were all non-spontaneous utterances produced by the children. This covers recitations of texts (e.g., of songs or of verse) as well as immediate imitations of a preceding adult utterance, whether explicitly elicited by the parent or initiated by the child. Also excluded were elicited completions from the child, either of texts or of words in non-text utterances.

\subsection{Type of Utterances Included in the Analyzed Corpora}

The utterances included in the analysis contained verbs and stative predicates (in the following: verbs) accompanied by IOs with the preposition $l e-$, in a canonical VI word order. Bare nouns-phrases lacking the obligatory preposition $l e$ - were not included even when their semantics was that of a dative object. In a few cases the recording was ambiguous whether or not the child produced the preposition; these were included. The present study focussed on the first 10 different verbs getting IOs.

\subsection{Coding for Semantic Category: Thematic Roles of the Indirect Objects}

The semantic similarity of the indirect objects was measured by the similarity in thematic roles. The coding categories are presented in Table 1, together with some examples. They are based on the semantic categories listed for indirect-dative objects in Berman (1982), Borer and Grodzinsky (1986) and Glinert (1989: 148-163). There are 10 categories and 9 idiosyncratic items, each separately coded. 
Table 1: Semantic Categories of Indirect Objects

\begin{tabular}{ll} 
Category & Predicates getting such an IO \\
\hline recipient & natan ('give'), hevi ('bring'), qana ('buy') \\
addressee & amar ('say'), hitkasher ('call'), hera ('show') \\
possessor & haya ('be'), eyn ('not be'), shayak ('belong') \\
connectee & xiber ('attach'), ciref ('append'), kashar ('tie') \\
joinee & hictaref ('join'), hitlava ('accompany') \\
referent & hityaxes ('refer'), hitkaven ('allude'), qar'a ('shem') \\
('name') & azar ('help'), patax ('open'), bana ('build') \\
beneficiary & qar ('cold'), qashe ('difficult'), tov ('good') \\
experiencer & nafal ('fall'), niknas ('enter'), hitkalkel ('spoil') \\
ethical & \\
$=$ affectee, malfactee & \\
reflexive & yashav ('sit'), hitbayesh ('be ashamed'), nax ('rest') \\
$=$ atonomous agent & \\
idiosyncratic & hirbic ('hit'); qara ('happen'); xika ('wait'); asur \\
& ('forbidden'); hirsha ('allow'); magia ('due'); maspiq \\
& ('enough'); matim ('fit'); dome ('like')
\end{tabular}

\section{Results}

\subsection{Facilitation among the first 10 VI types learned}

The first hypothesis tested was that earlier-learned verbs facilitate the learning of further verbs in the same syntactic pattern. The measure of facilitation used was the pace of the temporal spread of the VI construct across different verbs, expecting a gradual acceleration as a child learns to produce VIs with more verbs. For each child, the cumulative number of different verbs with IOs was plotted as a function of age at first producing the relevant combination for each verb, up to the 10th verb learned. In a few cases there was a tie between several verbs for the 10th verb status; in this case all tied verbs were included in the analysis. Two trendlines were fitted to each cumulative growth curve by the Excel program: a linear one and a power-law function.

Figure 1 presents the growth curve of a child (F-8), with a linear and a power-law trendline fitted to the cumulative developmental curves. 


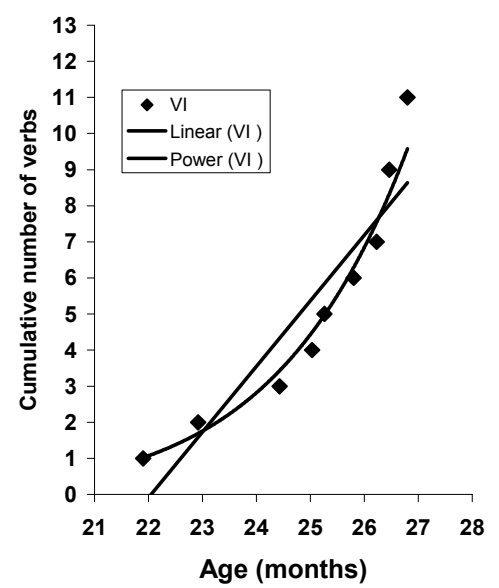

Figure 1. Cumulative number of different verbs in the VI pattern as a function of age in a child $(\mathrm{F}-8)$

The data of this child is representative of the results as a whole; she was chosen to illustrate the group findings as the difference between the variance explained by the linear and the power-law functions for her graph was the closest of all children to the mean of the group.

In all 14 children the cumulative frequency of the first 10 verbs in the VI pattern showed an accelerating function. There was a very good fit of the power function to the cumulative distribution. The mean fit of an accelerating power-function was $R^{2}=0.93$ of the variance $(S D=0.06)$. The mean fit of a linear function was $R^{2}$ $=0.79$ of the variance $(S D=0.13)$. On average the power function explained 14.3 percent more of the variance than the linear function $(S D=0.08)$. The comparison of the fit of the power function with the fit of the linear function by paired two-tailed $t$-test revealed that the difference is highly significant $(t(12)=7.00, p<$ 0.001 ). In all 14 children the power function had a better fit to the accumulative graph relative to a linear function. Against a null hypothesis that graphs will be non-accelerating, this result is significantly higher than chance by binomial sign test $(p<0.001)$.

It might be summarized that there is strong evidence for a gradually accelerating spread of the syntactic pattern over different verbs, and hence for facilitation of learning, among the first 10 verbs in the VI pattern. The more verbs a child already knows how 
to combine with an indirect object, the faster she can learn a new verb in the same pattern.

\subsection{Testing the hypothesis that facilitation is based on semantic analogy}

The first 10 verbs learned in the VI pattern by each child are presented in the appendix. All indirect objects produced by the children were coded for their semantic role, the coding based on the complete utterance of which they formed a part, as well as on the contextual notes accompanying it. The coding was performed independently by two coders. The percentage of agreement between the two coders was 93.6 percent. Disagreements were discussed and resolved. Table 2 presents the verbs learned by the children as one of the first 10 verbs in the VI pattern, classified by the semantic role of the indirect object.

Table 2: Verbs Learned by at least One Child as One of the First Ten Verbs with an IO, by the Semantic Role of the IO

Semantic Role

Verbs

of Indirect Object (number of children using verb)

\begin{tabular}{ll}
\hline Recipient & natan ('give') (13); hevi ('bring') (10); laqax ('take') (4); \\
& qana ('buy') (3); hixzir ('return') (1); masar ('hand') (1) \\
Addressee & hera ('show') (1) \\
Possessor & haya ('be') (13); eyn ('not-be') (3) \\
Connectee & hidbik ('glue') (2); xiber ('attach') (1) \\
Joinee & [none produced] \\
Referent & qar'a (shem) ('call') ('name') (1) \\
Beneficiary & asa ('make/do') (5); azar ('help') (5); patax ('open') (4); \\
& sam ('put') (4); horid ('take down') (3); hekin ('prepare') \\
& (2); hilbish ('dress-tr') (2); hoci ('take out') (2); qilef \\
& ('peel') (1); shamar ('guard') (1); shar (Ising') (1); shatal \\
& ('plant') (1); siper (sipur) ('tell story') (1); xipes ('search') \\
& (1); yarad ('get down') (1); bana ('build') (1); heziz \\
& ('move-tr') (1); hikri ('read-tr') (1); ciyer ('draw') (1). \\
& koev ('painful') (6); kashe ('difficult') (3); xam ('warm') \\
& (3); kaas ('get angry') (1); qar ('cold') (1); kaved ('heavy') \\
& (1); taim ('tasty') (1). \\
& nafal ('fall') (5); af ('fly') (1); digdeg ('tickle') (1); halak \\
Ethical (=affectee, & ('go') (1); hifria ('interfere') (1); histovev ('turn-rfx') (1); \\
malfactee) & hitkalkel ('spoil-rfx') (1); naga ('touch') (1); nigmar \\
& ('finish-pass') (1); niknas ('enter') (1); nishbar ('broke') \\
& (1); yaca ('get out') (1). \\
& raca ('want') (1) \\
Reflexive & hirbic ('hit') (3) \\
Idiosyncratic-1 & qara ('happen') (2) \\
Idiosyncratic-2 & xika ('wait') (3) \\
Idiosyncratic-3 & asur ('forbidden') (1) \\
Idiosyncratic-4 &
\end{tabular}


Idiosyncratic-5

Idiosyncratic-6

Idiosyncratic-7

Idiosyncratic-8

Idiosyncratic-9

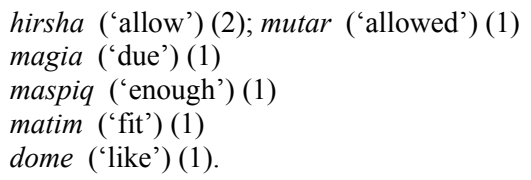

In order to test the hypothesis that facilitation is based on semantic analogy, three different examinations were performed:

1. The feasibility of semantically based facilitation was checked by estimating the amount of semantic homogeneity among the first 10 IOs;

2. The amount of semantic homogeneity was correlated with the amount of facilitation found;

3. Semantic homogeneity was eliminated from among the first 10 IOs produced, and the residual series was tested for facilitation.

\subsection{Semantic Similarity among the First 10 Indirect Objects as Measured by Thematic Roles}

The first test of the hypothesis that facilitation is based on semantic analogy consisted of checking the feasibility of semantic analogy by examining the amount of semantic homogeneity among children's first 10 IOs. This examination is an indirect test of the semantic analogy hypothesis; it merely asks whether children's laterproduced IOs could have been modeled on previously-produced ones, based on a similarity in semantic role. A basic condition is that all later-produced IOs would indeed have a semantically similar antecedent among previously-produced IOs. We asked how many of children's indirect objects had at least one semantically related antecedent among the IOs learned before it that could potentially serve as its source of transfer. Table 3 presents the distribution of the sample according to the number of different types of semantic roles each child expressed among their first 10 different IOs. 
Table 3: Distribution of Number of Different Semantic Roles among the First Ten IOs in the Sample

\begin{tabular}{ccc}
\hline $\begin{array}{c}\text { Number of different } \\
\text { semantic roles }\end{array}$ & Number of children & Percent of sample \\
\hline 1 & 0 & $0.0 \%$ \\
2 & 0 & $0.0 \%$ \\
3 & 0 & $0.0 \%$ \\
4 & 2 & $14.3 \%$ \\
5 & 4 & $28.6 \%$ \\
6 & 5 & $35.7 \%$ \\
7 & 1 & $7.1 \%$ \\
8 & 2 & $14.3 \%$ \\
9 & 0 & $0.0 \%$ \\
10 & 0 & $0.0 \%$ \\
\hline
\end{tabular}

All children expressed at least 4 different semantic roles by their first 10 IO types, and most expressed 6 or more. The mean number of different semantic roles represented among the first 10 IO types was $5.79(S D=1.25)$. The large number of different semantic categories among the first 10 different IOs implies that each category consisted of only a few exemplars for a given child. On the average, there were 1.72 different IOs per semantic category, less than 2 per category.

Out of 9 second- to tenth-learned IOs in the VI construction, only a mean of $4.21(46.8 \%)$ had one or more antecedents in the form of an IO belonging to the same thematic category, while 4.79 $(53.2 \%)$ of these later-learned IOs were not preceded by any semantically similar antecedent. Namely, the majority of laterlearned IOs were without a single semantic antecedent among previously learned ones.

The significance of these results is that the basic conditions for the workings of semantic analogy as a universal explanation of the accelerating growth curves do not exist in the set of indirect objects comprising children's first 10: more than half of the IOs in the curve cannot have been learned on the basis of semantic analogy to a previously produced one. At the least, semantic similarity cannot, by itself, account for the accelerated learning seen in the growth curves. However, the results leave open the possibility that semantic similarity does play at least some part in the transfer and facilitation observed in the acquisition process. This possibility is explored in the following sections. 


\subsection{Correlation of Semantic Variability with Acceleration}

The next question explored was, does semantic similarity have a significant effect on facilitation of learning? As seen in Table 3, there were individual differences among the children of the sample in the amount of semantic homogeneity of their first 10 IOs. This fact permits a more direct estimate of the role of semantic analogy in facilitation of learning, exploiting the existing variability.

On the hypothesis that semantic homogeneity assists learning, it is expected that the more homogenous semantically a child's first 10 IOs are, the more the learning of this series will be facilitated. Namely, the amount of semantic similarity among the first 10 IOs should have a significant positive relation with the facilitation of learning observed in a child's learning curve. As an estimate of the size of a possible semantic factor in transfer, a correlation coefficient was computed between the number of different semantic roles of a child's first 10 IOs and the amount of acceleration of learning in that child's development. Acceleration was measured by the difference between the percent of variance explained by the power-law function $\left(R^{2}\right)$ and the percent of variance of the growth curve explained by the linear function.

The correlation between number of different semantic roles of the first 10 indirect objects and the estimate of acceleration in the graphs was not significant $(r(12)=-0.20, p>0.05)$. Namely, the semantic variability of the first 10 IO types did not correlate significantly with the amount of facilitation previously-learned IOs provided for later-learned ones. In addition, the size of the effect was very small $(4 \%)$, indicating that semantic similarity cannot have more than a minor contribution to the facilitation of the learning process.

\subsection{Controlling for the Effect of Semantic Similarity on Acceleration of Learning}

A different test of the role of semantic similarity in facilitating learning is provided by the fact that some IOs in each child's series of 10 are semantically similar to some antecedents, while others are not. The question was: To what extent do the presence of items with semantic antecedents account for the acceleration of the growth curves? As we saw above, about 47 percent of all secondto tenth-learned IOs did have one or more antecedents in the form of an IO belonging to the same thematic category. In order to discount the possibility that such semantic similarity could have aided 
children's learning, we removed all IOs with semantic antecedents from the series and tested the remaining items once again for acceleration. If the similarity in the formal pattern of verb-IO constructions, regardless of their semantics, is a sufficient basis for transfer of learning, the remainder-graph will also show acceleration. If, however, similarity in the formal pattern among the VI items is not enough to feed facilitation of learning, the remaindergraph will not accelerate, demonstrating that the acceleration in the original growth curve should be attributed to the semantically similar items it contained.

The results of this analysis showed that the deletion of items possessing semantic antecedents had a negligible effect on the growth curves. Among the items without semantic antecedents, the mean fit of an accelerating power-function was $R^{2}=0.92$ of the variance $(S D=0.04)$. The mean fit of a linear function was $R^{2}=$ 0.85 of the variance $(S D=0.12)$. On the average, the power function explained 7.4 percent more of the variance than the linear function $(S D=0.09)$. The comparison of the fit of the power function with the fit of the linear function by paired, two-tailed $t$-test revealed that the difference is highly significant $(t(12)=3.15, p<$ $0.01)$. Namely, when items with semantic antecedents are removed from the series, the difference between the fit of a power-function and a linear-function stays highly significant, indicating that the acceleration in the original growth curve did not originate in the semantically similar items it contained. Instead, it is similarity in the formal pattern among VI sentences that in all probability underlies the observed transfer and facilitation of learning.

\section{Discussion}

The present findings regarding the gradually accelerated temporal spread of the dative object over different verbs replicate previous findings on transfer and facilitation in learning syntactic combinations (e.g., Abbot-Smith \& Behrens 2003; Kiekhoefer 2002; Ninio 1999; Ninio \& Keren-Portnoy 2002). These findings support the claim in the learning literature that all new learning involves transfer based on previous learning of similar contents (Bransford et al. 1999).

It is a possibility to be considered that the accelerating growth curves could reflect an artifact due to undersampling at the earlier ages, as younger children produce fewer utterances during the same observational period and there is reduced likelihood of picking up any given VI combination that the children know. In fact, 
the present study combined parental diaries with an observational schedule, making it highly unlikely that the accelerating growth curves are sampling artifacts. In addition, accelerating growth patterns are obtained with very dense observational sampling (e.g., Abbot-Smith \& Behrens 2003; Kiekhoefer 2002) as well as with full-blown parental diary studies conducted by highly trained professional observers (Bowerman 1976; Braine 1963; and see Ninio 1999, based on Tomasello's 1992 diary study of his daughter). Lastly, simple language increase would predict that the growth curves should accelerate equally for all constructions learned in the same period, which they do not appear to do.

Another possibility to be considered is that the accelerating growth pattern reflects an input frequency effect. Under this assumption, children need to hear a "critical mass" of input sentences for a given verb in a particular syntactic pattern before they are able to produce a sentence of their own using the verb in the relevant construction. As the input frequency distribution is highly skewed, there are typically only a small number of high frequency verbs, but increasingly more verbs at lower frequencies. A graph plotting verb frequency against the number of verbs with a given frequency is non-linear. If the order of acquisition mirrors input frequency, this could mean that children will initially learn a small number of high frequency verbs, but as they begin to learn lower frequency verbs, many more verbs reach that "critical mass" leading to an exponential increase in cumulative verb type frequency.

As there is no evidence that children need a "critical mass" of modeled utterances in the input in order to learn a given verb in a particular syntactic construction, the question to ask is whether there is in fact a correlation of input frequency with order of acquisition. For the particular syntactic pattern investigated in the present instance, Hebrew indirect object, the surprising answer is that input frequency influences mainly the acquisition of very firstlearned verb. For verbs learned later on, the impact of input frequency drops dramatically (Ninio 2003). As a concrete example, let us examine the verbs learned by the child F-8 as her $1^{\text {st }}$-to- $11^{\text {th }}$ verbs. She indeed learned the verb most frequent in the pooled maternal input, natan ('give'), as her first verb with an IO. She also learned the second most-frequent maternal verb, haya ('be'), among her $1^{\text {st }}$-to- $11^{\text {th }}$ verbs (as her $3^{\text {rd }}$ verb). However, at this point the effect of input frequency on her acquisition all but disappears. She does not learn to produce at this period the VI pattern with the next 13 most frequent verbs in the maternal input, namely, with the 
verbs hevi ('bring'), asa ('make/do'), hera ('show'), siper ('tell a story'), higid ('say'), azar ('help'), sam ('put'), qara ('call') (i.e., 'name'), shar ('sing'), amar ('say'), eyn ('not-be'), qara ('happen') and masar ('hand'). Instead, she learns much less frequent items such as qashe ('difficult'), xam ('warm'), kaav ('hurt'), hirbitz ('hit'), qana ('buy') and so on. The data of the other children of the sample are similar to this child's. Apparently, input frequency ceases to be a decisive factor in acquisition once the first verb, or maybe the two or three first verbs, are learned in this new syntactic configuration. The results clearly do not support the idea that verbs are learned in the order they reach a "critical mass" in the input, or that the acceleration of the growth curves is to be attributed to the growing number of verbs achieving a "critical mass" for learning.

We might conclude that the accelerating growth curves are probably not artifacts of under-sampling, nor are they reducible to an input frequency effect. Instead, they appear to point to the operation of transfer in learning. As in other studies, the findings of this study were that the more verbs children already know to combine in the verb-indirect object pattern, the faster they learned new ones in the same pattern. The acceleration of growth curves for different verbs appearing within the same syntactic configuration supports a learning-theoretical conceptualization of syntactic development. Apparently, multiword constructions involving some verb are learned from the input in an item-specific manner for each verb separately; however, this is piecemeal learning assisted by transfer. The sources for transfer are other lexical items previously learned in the same construction.

The learning of argument-structure constructions is not usually treated in the literature dealing with language acquisition as a lexically specific task, despite the fact that in theoretical linguistics it is long acknowledged that the allocation of argument-structure constructions to individual verbs is inherently arbitrary and, hence, a lexical feature of each verb (Chomsky 1981). Like with the acquisition of vocabulary, this task appears to be facilitated by previously learned items, as evidenced by the accelerating growth curves in the former as in the latter (e.g., Nelson 1973). The similarity between the vocabulary acquisition and the learning of basic syntax for individual lexical items strongly supports the lexicalist view of theoretical linguistics that takes the form of a requirement that individual "subcategorization frames" of verbs be registered in their lexical entry (see also Bresnan 1978). 


\subsection{Semantic similarity does not play a crucial role in transfer of learning in syntactic development}

The results of the present study also replicate previous findings regarding the relative insignificance of semantic similarity in transfer and facilitation of learning in early syntactic development (Ninio 2003; Abbot-Smith et al. 2004). The replication shows that the absence of a significant semantic similarity effect is not unique to transitive constructions such as the verb-object pattern but apparently characterizes syntactic development in general, at least at its early stages. The results indicate that semantic analogy is not a necessary condition for facilitation and transfer of learning. The similarity in the formal pattern among the old and newly learned items appears to be sufficient by itself for transfer and facilitation to take place. This conclusion gives pride of place to the construction as a schematic format, in the process of acquisition. The formal pattern formed by the combination of a verb with an indirect object (verb $+l e+$ noun) is identical in the case of two different verbs: this is what is meant in theoretical linguistics by the term "subcategorization frame". In the case of the Hebrew dative object, the presence of the obligatory clitic preposition le- probably strongly contributes to the similarity in the formal pattern of different VI phrases. It seems that learning a few verbs with a le-object is enough to make the learning of further ones faster and easier, regardless of the meanings expressed by the verbs or by the leobjects.

This conclusion should be qualified to some extent. Although fine grained semantic similarity is absent from the old and new items forming particular sequences of learning, it is possible that global semantic similarity is still present among them. Some of the semantic subcategories of the IO share various local similarities (e.g., recipient and addressee, recipient and possessor, affectee and beneficiary), and it is possible that children pick up on these in some cases when they use old learning to assist new learning by analogy. Still, this more general semantic effect cannot account for the whole pattern of facilitation found in the study, as in many cases it is hard to find even traces of similarity of meaning among successive items, such as between the prototypical recipient and the experiencer of qar ('cold'), the reflexive agent of hitbayesh ('be ashamed'), or the idiomatic object of dome ('like, similar').

Moreover, it is possible that semantic similarity may facilitate transfer even if it is not necessary for it. In the present naturalistic paradigm, the findings can only indicate that transfer of learning is 
possible even when the relevant structures are not semantically similar - in other words, that semantic similarity is not a necessary condition for transfer. The results cannot show that transfer is not operative in transfer in addition or instead of formal similarity. This possibility could be ruled out only by experimental work.

Finally, the high semantic variability of the first ten VI types makes it highly unlikely that they are learned on any but an itemspecific basis. However, the results demonstrate that there is no contradiction between item-based learning and facilitation. It seems that item-specific knowledge can be used to deal with other lexical items in a process of item-to-item transfer and analogy. Thus, the key to facilitated learning does not need to be categorization, abstraction, generalization or any other change from concrete to abstract representation of grammatical knowledge; it is enough to have previous experience with a similar learning task. Apparently, breaking into a new syntactic combination means solving the conceptual problems associated with that pattern once and for all. Learning the construction with the first one or two verbs requires the most effort, but once that is done, the child's system is ready for transfer of learning, and the learning of further items in the same construction is done almost effortlessly.

In conclusion, the results of this study support a learning theory of syntactic development. Learning is lexical-specific and concrete, but also transferable through structural analogy. This conclusion fits well the current lexical-specific approach to early argument structure constructions in young children, and also the lexical emphasis of theoretical linguistics regarding the best description of adult syntactic knowledge. It has been long accepted that individual "subcategorization frames" of verbs must be registered in their lexical entry (Bresnan 1978; Chomsky 1981, and see Baltin 1989 for a discussion). The present proposal is for a learning process that puts subcategorization frames into the many entries of the lexicon with a relatively low expenditure of effort, due to the operation of item-to-item analogy and transfer.

Received 5 May 2000

Revision received 7 August 2000

Hebrew University, Jerusalem 
Appendix: The First Ten Verbs Learned in the VI Pattern by Each Child

\begin{tabular}{|c|c|}
\hline Child & First 10 verbs in the VI pattern \\
\hline $\mathrm{F}-01$ & $\begin{array}{l}\text { natan ('give'); haya ('be'); azar ('help'); hixzir ('return'); kashe } \\
\text { ('difficult'); hirbic ('hit'); qara ('happen'); koev ('painful'); xika } \\
\text { ('wait'); niknas ('enter') }\end{array}$ \\
\hline M-02 & $\begin{array}{l}\text { hevi ('bring'); patax ('open'); haya ('be'); horid ('take down'); asa } \\
\text { ('make/do'); asur ('forbidden'); hirsha ('allow'); natan ('give'); } \\
\text { sam ('put'); magia ('due') }\end{array}$ \\
\hline $\mathrm{F}-03$ & $\begin{array}{l}\text { naga ('touch'); nafal ('fall'); azar ('help'); kashe ('difficult'); } \\
\text { natan ('give'); eyn ('not-be'); haya ('be'); hidbik ('glue'); nigmar } \\
\text { ('finish-pass'); shamar ('guard') }\end{array}$ \\
\hline $\mathrm{F}-04$ & $\begin{array}{l}\text { natan ('give'); siper (sipur) ('tell'); hekin ('prepare'); sam ('put'); } \\
\text { koev ('painful'); qar ('cold'); raca ('want'); yarad ('get down'); } \\
\text { maspiq ('enough'); laqax ('take') }\end{array}$ \\
\hline M-05 & $\begin{array}{l}\text { hevi ('bring'); xam ('warm'); nafal ('fall'); asa ('make/do'); eyn } \\
\text { ('not-be'); horid ('take down'); laqax ('take'); hitkalkel ('spoil- } \\
\text { rfx'); natan ('give'); haya ('be') }\end{array}$ \\
\hline M-06 & $\begin{array}{l}\text { hevi ('bring'); natan ('give'); azar ('help'); shar ('sing'); eyn ('not- } \\
\text { be'); haya ('be'); shatal ('plant'); histovev ('turn-rfx'); qana } \\
\text { ('buy'); masar ('hand') }\end{array}$ \\
\hline M-07 & $\begin{array}{l}\text { natan ('give'); azar ('help'); hilbish ('dress-tr'); qana ('buy'); koev } \\
\text { ('painful'); hevi ('bring'); xiber ('attach'); kaas ('get angry'); haya } \\
\text { ('be'); bana ('build') }\end{array}$ \\
\hline $\mathrm{F}-08$ & $\begin{array}{l}\text { natan ('give'); kashe ('difficult'); haya ('be'); xam ('warm'); koev } \\
\text { ('painful'); hirbic ('hit'); qana ('buy'); patax ('open'); hirsha } \\
\text { ('allow'); matim ('fit') }\end{array}$ \\
\hline F-09 & $\begin{array}{l}\text { natan ('give'); hoci ('take out'); xika ('wait'); azar ('help'); xipes } \\
\text { ('search'); hevi ('bring'); sam ('put'); patax ('open'); qilef } \\
\text { ('peel'); haya ('be') }\end{array}$ \\
\hline F-10 & $\begin{array}{l}\text { hevi ('bring'); sam ('put'); hikri ('read-tr'); xika ('wait'); hekin } \\
\text { ('prepare'); hilbish ('dress-tr'); haya ('be'); heziz ('move'); hifria } \\
\text { ('interfere'); hidbik ('glue') }\end{array}$ \\
\hline F-11 & $\begin{array}{l}\text { nafal ('fall'); natan ('give'); laqax ('take'); yaca ('get out'); haya } \\
\text { ('be'); horid ('take down'); asa ('make/do'); nishbar ('broke'); } \\
\text { hevi ('bring'); hera ('show') }\end{array}$ \\
\hline M-12 & $\begin{array}{l}\text { natan ('give'); hevi ('bring'); halak ('go'); taim ('tasty'); haya } \\
\text { ('be'); dome ('like'); kaved ('heavy'); af ('fly'); ciyer ('draw'); } \\
\text { hoci ('take out') }\end{array}$ \\
\hline M-13 & $\begin{array}{l}\text { qara ('happen'); haya ('be'); laqax ('take'); hirbic ('hit'); hevi } \\
\text { ('bring'); koev ('painful'); asa ('make/do'); mutar ('allowed'); } \\
\text { nafal ('fall'); natan ('give') }\end{array}$ \\
\hline F-14 & $\begin{array}{l}\text { natan ('give'); nafal ('fall'); hevi ('bring'); qar'a (shem) ('name'); } \\
\text { haya ('be'); asa ('make/do'); koev ('painful'); patax ('open'); } \\
\text { digdeg ('tickle'); xam ('warm') }\end{array}$ \\
\hline
\end{tabular}




\section{Notes}

* Department of Psychology, The Hebrew University, Jerusalem 91905, Israel. E-mail: msninio@mscc.huji.ac.il. This research was supported in part by a grant from the Spencer Foundation. The data presented, the statements made, and the views expressed are solely the responsibility of the author. I wish to thank the mothers and the children who participated in the study, the students and research assistants who helped in the collection of the child language corpora, and Tamar Arnon who participated in the analysis of the child utterances as part of the requirements of her Master's thesis.

\section{References}

Abbot-Smith, Kirsten and Heike Behrens

2003 Construction conspiracies in the acquisition of the German passive. Unpublished manuscript, Max Planck Institute for Evolutionary Anthropology, Leipzig, Germany.

Abbot-Smith, Kirsten, Elena V. Lieven, and Michael Tomasello

2004 Training 2;6-year-olds to produce the transitive construction: The role of frequency, semantic similarity and shared syntactic distribution. Developmental Science 7, 48-55.

Akhtar, Nameera, and Michael Tomasello

1997 Young children's productivity with word order and verb morphology. Developmental Psychology 33, 952-965.

Allerton, D. J.

1978 Generating indirect objects in English. Journal of Linguistics 14, 21-33.

Baltin, Mark R.

1989 Heads and projections. In Mark R. Baltin, and Antony S. Kroch (eds.), Alternative conceptions of phrase structure. Chicago: University of Chicago Press, 1-17.

Ben-Shachar, Michael and Yosef Grodzinsky

2002 On the derivation of Hebrew double objects - a functional imaging investigation. Paper presented at the Conference of the North East Linguistic Society (NELS 33), Massachusetts Institute of Technology, Cambridge, MA.

Berman, Ruth A.

1978 Modern Hebrew Structure. Tel Aviv: University Publishing Projects.

1982 Dative marking of the affectee role: Data from modern Hebrew. Hebrew Annual Review 6, 35-59.

1985 The acquisition of Hebrew. In Dan I. Slobin (ed.), The Crosslinguistic Study of Language Acquisition, vol. 1. Hillsdale, NJ: Erlbaum, 255-371.

Bloom, Lois, Patsy Lightbown, and Lois Hood

1975 Structure and variation in child language. Monographs of the Society for Research in Child Development 40 (2, Serial No. 160).

Bolinger, Dwigt

1973 Ambient it is meaningful too. Journal of Linguistics 9, 261-270. 
Borer, Hagit and Yosef Grodzinsky

1986 Syntactic cliticization and lexical cliticization: The case of Hebrew dative clitics. In Hagit Borer (ed.), Syntax and Semantics Vol. 19: The Syntax of Pronominal Clitics. New York: Academic Press, $175-218$.

Botwinik-Rotem, Irena

2000 The thematic and categorial status of Ps: the dative, directional, locative distinction. Paper presented at the Fifth International Colloquium on Chamito-Semitic Languages (CAL 5). Paris, France.

Bowerman, Melissa

1973 Structural relations in children)s utterances: syntactic or semantic? In T. M. Moore (ed.), Cognitive Development and the Acquisition of Language. New York: Academic Press, 197-213.

1976 Semantic factors in the acquisition of rules for word use and sentence construction. In D. Morehead and A. Morehead (eds.), Directions in Normal and Deficient Child Language. Baltimore: University Park Press, 99-179.

1982 Reorganizational processes in lexical and syntactic development. In Eric Wanner, and Lila R. Gleitman (eds.), Language Acquisition: the State of the Art. Cambridge: Cambridge University Press, 319346.

Braine, Martin D. S.

1963 The ontogeny of English phrase structure: The first phase. Language 39, 1-13.

1976 Children's first word combinations. Monographs of the Society for Research in Child Development 41 (1, Serial No. 164).

Bransford, J. D., Brown, A. L., and Cocking, R. R. (eds.)

1999 How People Learn: Brain, Mind, Experience, and School. New York: National Research Council, National Academy of Sciences.

Bresnan, Joan W.

1978 A realistic transformational grammar. In M. Halle, J. Bresnan and G. Miller (eds.), Linguistic Theory and Psychological Reality. Cambridge, MA: MIT Press, 1-59.

Brown, Roger

1973 A First Language: The Early Stages. Cambridge MA: Harvard University Press.

Byrnes, James P.

1996 Cognitive Development and Learning in Instructional Contexts. Boston: Allyn and Bacon.

Childers, Jane B. and Michael Tomasello

2001 The role of pronouns in young children's acquisition of the English

Chomsky, Noam transitive construction. Developmental Psychology 37, 730-748.

1981 Lectures on Government and Binding. Dordrecht: Foris.

Clark, Eve V.

1978 Discovering what words can do. Papers from the Parasession on

Dabrowska, Ewa the Lexicon, CLS 14. Chicago: University of Chicago Press, 34-57.

2000 From formula to schema: the acquisition of English questions. Cognitive Linguistics 11, 83-102. 
Elman, Jeffrey L., Elizabeth Bates, Mark Johnson, Annette Karmiloff-Smith,

Domenico Parisi, and Kim Plunkett

1996 Rethinking Innateness. Cambridge, MA: MIT Press.

Fisher, Cynthia

1996 Structural limits on verb mapping: The role of analogy in children's interpretation of sentences. Cognitive Psychology 31, 41-84.

Gentner, Dedre and Arthur B. Markman.

1997 Structure mapping in analogy and similarity. American Psychologist 52, 45-56.

Glinert, Lewis

1989 The Grammar of Modern Hebrew. Cambridge: Cambridge University Press.

Goldberg, Adele E.

1995 Constructions: A Construction Grammar Approach to Argument Structure. Chicago: University of Chicago Press.

1999 The emergence of the semantics of argument structure constructions. In Brian MacWhinney (ed.), The Emergence of Language. Mahwah, NJ: Erlbaum, 197-212.

Gropen, Jess, Steven Pinker, Michelle Hollander, Richard Goldberg, and Ronald Wilson

1989 The learnability and acquisition of the dative alternation in English. Language 65, 203-257.

Hilaire, Geraldine and Sophie Kern

2002 Le role de l'analogie dans l'acquisition de la langue maternelle. ['The role of analogy in the acquisition of the first language'] $\mathrm{Pa}$ per presented at the Symposium on Analogy and Cognition, Toulouse, France.

Hirsh-Pasek, Kathy and Roberta M. Golinkoff

1996 The Origins of Grammar: Evidence from Early Language Comprehension. Cambridge, MA: MIT Press.

Ingram, David

1989 First Language Acquisition. Cambridge: Cambridge University Press.

Kiekhoefer, Kai

2002 The acquisition of the ditransitive construction. Paper presented at the Ninth International Congress for the Study of Child Language and the Symposium on Research in Child Language Disorders (IASCL/SRCLD), Madison, WI.

Landau, Idan

1994 Dative shift and extended VP-shells. Unpublished master's thesis, Tel-Aviv University, Ramat Aviv, Israel.

2002 The locative syntax of experiencers. Paper presented at the 18th Annual Meeting of the Israel Association for Theoretical Linguistics (IATL 18), Bar Ilan University, Ramat Gan, Israel.

Lyons, John

1968 Introduction to Theoretical Linguistics. Cambridge: Cambridge University Press.

MacWhinney, Brian

1982 Basic syntactic processes. In Stan Kuczaj (ed.), Language Development: Vol. 1. Syntax and Semantics. Hillsdale, NJ: Erlbaum, 73136. 
Maratsos, Michael P. and Mary A. Chalkley

1980 The internal language of children's syntax: The ontogenesis and representation of syntactic categories. In Keith E. Nelson (ed.), Children's Language, vol. 2. New York: Gardner Press, 127-214.

McClure, Kathleen and Julian M. Pine

2002 Examining the Verb Island hypothesis. Paper presented at the Ninth International Congress for the Study of Child Language and the Symposium on Research in Child Language Disorders (IASCL/SRCLD), Madison, WI.

Morris, William C., Garrison W. Cottrell and Jeffrey Elman

2000 A connectionist simulation of the empirical acquisition of grammatical relations. In Stefan Wermter and Run Sun (eds.), Hybrid Neural Symbolic Integration. Berlin: Springer Verlag, 175-193.

Nelson, Katherine

1973 Structure and strategy in learning to talk. Monographs of the Society for Research in Child Development 141 (38,1-2).

Ninio, Anat

1988 On formal grammatical categories in early child language. In Yonata Levy, Izchak Schlesinger, and Martin D. S. Braine (eds.), Categories and Processes in Language Acquisition. Hillsdale, NJ: Erlbaum, 99-119.

1999 Pathbreaking verbs in syntactic development and the question of prototypical transitivity. Journal of Child Language, 26, 619-653.

2003 Analogy and transfer of learning as central processes in syntactic development. Invited article for a special issue of Revue d'Intelligence Artificielle ('RIA): Regards Croises sur l'Analogie, edited by K. Duvignau, O. Gasquet \& B. Gaume, 17, 813-821.

2005 Testing the role of semantic similarity in syntactic development. Journal of Child Language 32, 1-27.

Ninio, Anat and Tamar Keren-Portnoy

2002 Mastering the syntax of pathbreaking verbs delays learning others of the same kind. Paper presented at the Ninth International Congress for the Study of Child Language and the Symposium on Research in Child Language Disorders (IASCL/SRCLD), Madison, WI.

Pinker, Steven

1984 Language Learnability and Language Development. Cambridge, MA: Harvard University Press.

1989 Learnability and Cognition: the Acquisition of Verb-argument Structure. Cambridge MA: Harvard University Press.

Pustejovsky, James

1991 The generative lexicon. Computational Linguistics 17, 409-441.

1995 An exploration into the application of dynamic systems modelling to language acquisition. In Maaike Verrips, and Frank Wijnen (eds.), Approaches to Parameter Setting. Amsterdam Series in Child Language Development, vol. 4. Amsterdam: Institute of General Linguistics, 107-134.

Schlesinger, Izchak M.

1971 The production of utterances and language acquisition. In D. I. Slobin (ed.), The Ontogenesis of Grammar: A Theoretical Symposium. New York: Academic Press, 63-101. 
Shibatani, Masayoshi

1996 Applicatives and benefactives: A cognitive account. In Masaoshi Shibatani and Sandra A. Thompson (eds.), Grammatical Constructions: Their Form and Meaning. Oxford, Oxford University Press, 157-194.

Singley, Mark K. and John R. Anderson

1989 The Transfer of Cognitive Skill. Cambridge, MA: Harvard University Press.

Slobin, Dan I.

1985 Crosslinguistic evidence for the language-making capacity. In Dan I. Slobin (ed.), The Crosslinguistic Study of Language Acquisition, vol. 2. Hillsdale, NJ: Erlbaum, 1159-1249. Tomasello, Michael

1992 First Verbs: A Case Study of Early Grammatical Development. Cambridge; Cambridge University Press.

1998 The return of constructions. Journal of Child Language 25, 431447.

2000 Do young children have adult syntactic competence? Cognition 74 209-253.

Tomasello, Michael and Daniel Stahl

2004 Sampling children's spontaneous speech: how much is enough? Journal of Child Language 31, 101-121. 